\title{
Frailty: what the South African surgeon needs to know
}

\author{
NL George, ${ }^{1}$ GD Nethathe ${ }^{2}$ \\ 1 Specialist Anaesthesiologist, Private Practice \\ 2 Senior Clinical Lecturer, Division of Critical Care, School of Clinical Medicine, University of the Witwatersrand, \\ Johannesburg, South Africa. Department of Anaesthesia and Perioperative Medicine, Royal Brisbane and Women's Hospital, \\ Brisbane, Australia
}

Corresponding author: Ngozi Leopold-George (ngoztonye@yahoo.com)

\begin{abstract}
Summary
Frailty is a state characterised by diminished physiological reserve that leaves one vulnerable to external stressors such as surgery and delays recovery thereof. Frailty assessments are proving to be more valuable in predicting poor perioperative outcomes than other well-known perioperative risk assessment tools. Frailty and comorbidity are interlinked as increased number of comorbidities are associated with higher levels of frailty but are distinct entities as frailty can exist without multiple comorbidity. It is therefore important that screening tools that allow for quick identification of frail individuals become commonplace in the perioperative environment. Identification of these frail individuals should lead to vigilance in preventing perioperative complications and allow for interventions that will reduce morbidity and lead to better outcomes.
\end{abstract}

Keywords: frailty, surgery, elderly, assessments, clinical frailty scale, intraoperative complications

\section{Introduction}

In 2010, two thirds of the world's population above the age of 60 lived in developing countries. ${ }^{1}$ The World Health Organisation (WHO) reports that the number of people above the age of 60 will double by $2050 .^{2}$ In the United States over $40 \%$ of surgeries are performed on elderly patients. ${ }^{3}$ The identification and management of conditions that impact on these patients' surgical and anaesthetic risks may improve outcomes. ${ }^{4}$ The term 'frail elderly' was adopted by the Federal Council on Ageing and is defined as "persons, usually but not always, over the age of 75 , who because of an accumulation of various continuing problems often require one or several supportive services in order to cope with daily life". ${ }^{5}$ Frailty is the depletion of physiological and functional reserve across many organ systems leading to a diminished capacity to withstand environmental stressors such as surgery. ${ }^{6}$ It is not synonymous with ageing and is an independent predictor of mortality, morbidity, and increased length of stay perioperatively. ${ }^{7}$

An estimated 6.4 million South Africans are living with HIV. ${ }^{8}$ Age-related diseases have been noted to affect younger adults infected with HIV., ${ }^{9,10}$ South Africa additionally has a high burden of trauma which has implications related to surgery, critical care services and disability. ${ }^{11}$

Worldwide, the prevalence of frailty is quoted between
4-59.1\% depending on the population sampled and the tool used. ${ }^{12}$ A higher prevalence is reported among hospitalised, surgical populations. ${ }^{13}$

Most studies using any of the validated frailty measuring tools have been conducted in developed countries with few published studies in the developing world and fewer still in Africa. ${ }^{12,14}$

\section{Pathophysiology of factors associated with frailty}

The pathophysiology of ageing involves complex multiple mechanisms at a molecular and cellular level. These include cellular senescence, genomic instability, stem cell exhaustion, altered intercellular communication and decline of mitochondrial function and DNA copy number. ${ }^{14,15}$ The result is a reduction in energy production and reserves, increased free radical production and increased rates of apoptosis. ${ }^{15}$

Age related changes to the cardiovascular system can lead to orthostatic hypotension which predisposes to falls, a reduction in respiratory reserve can lead to atelectasis and pneumonia. Autonomic dysfunction and impaired autoregulation of cerebral perfusion leads to increased risk of postoperative cognitive disorders, stroke and injury. A decline in renal blood flow and increased occurrence of prostatic hypertrophy 
increases the risk of renal dysfunction and urinary tract infections. Reduced muscle and strength predispose to falls, immobility, venous thromboembolism and pressure injury which may lead to increased hospital length of stay and disability. ${ }^{16}$

Functional reserve allows the body to compensate and adapt to environmental stressors thus restoring homeostasis, the loss thereof impedes homeostasis and slows recovery from physiological stressors. Frailty increases with the number of impaired systems rather than the number of impairments in any one particular system. ${ }^{14}$

When reserve capacity is diminished the ability to respond and recover from stressors such as surgery, severe illness or injury may be prolonged or not occur at all. ${ }^{14}$

The dysregulation of immune and endocrine systems have also been implicated as well as the maldistribution and dysregulation of immune cells leading to higher levels of cytokines in the body., ${ }^{4,14}$

Sarcopenia and cachexia are closely related to frailty. Sarcopenia, a progressive loss of muscle mass in combination with loss of strength and/or physical performance is considered a hallmark of frailty. ${ }^{5}$ Cachexia is a catabolic syndrome associated with underlying illness and is distinguished from sarcopenia as sarcopenia is a more moderate loss of muscle mass with little to no adipose tissue loss. ${ }^{5,9}$ Loss of skeletal function and mass are a result of age-related inflammation and hormonal changes which include decreased growth hormone, insulin-like growth factor-1, dehydroepiandrosterone, sex steroids and increased cortisol levels. Low levels of Vitamin D have also been implicated. ${ }^{4}$

Frail patients are said to be in a constant state of chronic inflammation. $^{3}$ Elevated immune biomarkers such as interleukin-6 (IL-6), TNF-alpha and C-reactive protein have been noted in frail patients. ${ }^{4}$ Indicators of chronic inflammation such as low albumin have been used as measures of frailty. ${ }^{17}$ Pro-inflammatory cytokines promote protein catabolism and alter metabolic processes which have an effect on skeletal muscle, appetite, immunity, cognition and contribute to the development of anaemia. ${ }^{3}$ Immune system activation contributes to disordered coagulation leading to elevated serum markers of coagulation such as D-dimer, factor VIII and fibrinogen. Elevated neutrophil and monocyte cell counts have been demonstrated in frail elderly. ${ }^{4}$ Frailty has also been associated with impaired response to pneumococcal and influenza vaccines. ${ }^{14}$ None of these biomarkers are unique to frailty as many are also found in other conditions, making pathophysiological mechanisms leading to frailty harder to elucidate. $^{3}$

\section{Frailty and Comorbidity}

Frailty and comorbidity although related are distinct entities. Frailty can be present without comorbidity but there is overlap that becomes more evident with multiple comorbidities. ${ }^{14}$

Frail women were more likely to have had a prior diagnosis of coronary heart disease, stroke, diabetes mellitus, hypertension, arthritis, cancer and COPD in one study. ${ }^{18}$ With regards to HIV, the presence of the frailty phenotype was noted to be a predictor of AIDS or death in HIV infected men despite initiation of HAART. ${ }^{19}$ Frailty has also been linked to chronic kidney disease as well as visual and hearing impairment. ${ }^{20}$

Polypharmacy, which is common in the geriatric population is a possible contributor to frailty secondary to side effects experienced such as postural hypotension and myopathy but may also be a marker of multimorbidity. ${ }^{20,21}$

Frailty has shown strong associations with clinical and subclinical cardiovascular disease such as ischemia, left ventricular hypertrophy and reduced global left ventricular function. ${ }^{17} \mathrm{~A}$ large degree of atherosclerotic plaques also correlated with frailty. One purported mechanism is that atherosclerosis represents a state of inflammation which may lead to frailty as a result of the catabolic state and loss of muscle mass and appetite that ensues. ${ }^{17}$ Frailty was identified as a risk factor for mortality and prolonged institutionalisation after cardiac surgery. ${ }^{22}$ Congestive heart failure was most strongly associated with frailty with a sevenfold increase in the prevalence of this condition among the severely frail.

Preoperative frailty was shown to have a positive correlation with postoperative delirium. ${ }^{23}$ Depression has also been linked to frailty. ${ }^{18}$ The two conditions share common symptoms such as weight loss, low physical activity and exhaustion. Depression has been associated with the stimulation of proinflammatory psycho-neuroimmunological mechanisms and progressive muscle and functional loss from a reduction in physical activity.

Being underweight and overweight are both risk factors for frailty, as evidenced by a U-shaped relationship between body mass index and frailty, showing that extremes of body fat can be associated with lower muscle mass and strength. ${ }^{18}$ Not only is obesity a state of heightened inflammation, the obese may be micronutrient deficient and both conditions are associated with sarcopenia. "Sarcopenic obesity" is used to describe the state of being overweight but contrastingly having low muscle mass. ${ }^{18}$

\section{Social Factors Associated with Frailty}

Frailty has been reported to be higher in women. Notably elderly men have been found to be more likely to die than women at similar levels of frailty. ${ }^{24}$ This may be attributable to gender differences in genetic and acquired risks, immune and hormonal differences as well as gender differences in health reporting behaviour. ${ }^{18,24}$

A low family income, low level of education and being of African American descent was strongly associated with frailty. ${ }^{18}$ Education and race were, however, weak associations after adjustment and may have been indicators of social status and not race and education per se. Most studies on frailty have been conducted on Caucasian patients in developed Western countries and in these countries the prevalence has been found to be higher in Hispanic and African Americans. ${ }^{12,17}$ More 
studies are needed to further validate whether the prevalence is truly higher in other racial groups or whether this is a function of low socioeconomic status. ${ }^{4}$ Contrastingly strong associations between frailty and economic level and weak associations between frailty, education and occupation have been found..$^{24} \mathrm{~A}$ high socioeconomic status may afford an individual the resources to care for and improve their health delaying the progression to frailty. Lifestyle factors that are associated with low socioeconomic status such as smoking, and comorbidities such as HIV may account for the increased risk of frailty in low socioeconomic populations.

Cigarette smoke contains various chemicals which cause chronic inflammation leading to muscle wasting and the acceleration of ageing. In the WHI-OS smokers were 2.9 times as likely to become frail. ${ }^{18}$ Moderate alcohol intake was protective with moderate alcohol drinkers having up to a $31 \%$ lower risk than non-drinkers. Regular exercise has been found to be protective against frailty across all age groups. Individuals that were more physically active were found to have a lower risk of death. ${ }^{24}$

\section{Frailty and Disability}

Frailty is a potential cause and consequence of disability, but not all disabled persons are frail. ${ }^{20}$ Disability is difficulty or inability to complete one or more activities of daily living (ADL).$^{20}$ It can be a consequence of frailty or chronic disease secondary to changes in musculoskeletal function. ADL Disability at baseline has been shown to be more common in the frail $(5.9 \%)$ than non-frail $(0.7 \%){ }^{18}$

The main distinguishing point between frailty and disability is that frailty is dynamic and can be reversible whereas disability tends to be permanent. ${ }^{9}$ It is therefore important to identify frail patients and implement preventative strategies before they become disabled.

\section{Risk estimation in surgical patients}

The preoperative assessment provides a means of recognising those at risk in order to identify factors that can be optimised. ${ }^{19}$ It also presents an opportunity to discuss issues of harm and benefit as well an opportunity to map out the likely postoperative outcome.

Older surgical patients tend to have a high comorbidity burden and are at an increased risk of poor surgical outcomes, anaesthesia-related complications and death. ${ }^{4}$ The implications of these comorbidities on the perioperative course is not always apparent. Age alone as a criterion for selecting persons at risk of interventions has been shown to be less than ideal across a wide spectrum compared to frailty assessments. ${ }^{30}$

The American Society of Anaesthesiologists Physical Status (ASA-PS) classification system has been found to predict outcomes in surgical patients but mainly younger patients and with higher predictive value in those that score 3 or more. Frailty assessments have been shown to be a better indicator of overall health and physiological status as well as better predictors of postoperative complications, mortality and morbidity in the aged than other preoperative assessments such as the ASA-PS and the Revised Cardiac Risk Index (RCRI). ${ }^{26-28}$

Debate remains as to which frailty assessment tool is best to use in clinical practice to predict outcomes among surgical patients.

Correct assessment will identify the most vulnerable and may help facilitate discussions about realistic treatment goals, improve clinical risk prediction and inform health resource utilization practice.

\section{Assessing frailty}

Multiple models have been used to measure frailty. The two most popularised models are the frailty phenotype ${ }^{29}$ and frailty index or deficit accumulation model derived from data taken respectively from the Cardiovascular Health Study and the Canadian Study of Health and Aging. ${ }^{30}$

The frailty phenotype is defined as a syndrome based on phenotypic features which are unintentional weight loss, exhaustion, weakness (low grip strength), slow walking speed and low physical activity. Three or more out of the five features would make the diagnosis of frailty likely ${ }^{29}$ This definition has been criticised as being non-specific and placing too much emphasis on the physical nature of frailty. ${ }^{6}$ It also requires special equipment such as a dynamometer for grip strength measurement which may not always be readily available.

The deficit accumulation model views frailty as a state of vulnerability resulting from the accumulation of an individual's health deficits. The number of health deficits or impairments in an individual are added and divided by a predetermined number of possible health deficits to create a frailty index. ${ }^{31}$ It places more emphasis on psychosocial aspects, physical disability, comorbidity and cognitive impairment. ${ }^{32}$ The frailty index ranges between 0 and 1 with a deficit value above 0.25 generally accepted as frailty and higher values representing higher degrees of frailty. ${ }^{33}$ Concerns with this model include complexity precluding daily clinician use.

The addition of laboratory markers of chronic disease to increase the predictive value of preoperative frailty assessments has been suggested. ${ }^{34}$ Robinson's model is one such model that combines biomarkers such as anaemia and low albumin as well as factors such as comorbidity, cognition and a history of falls in the assessment. ${ }^{35}$

Screening tools have also been developed and validated to allow physicians to rapidly identify frailty. Some of these include the Clinical Frailty Scale, the Cardiovascular Health Study Frailty Screening Measure and the Gérontopôle Frailty Screening Tool. ${ }^{20}$

The Clinical Frailty Scale (CFS) was developed with the aim to address the need for a clinician friendly screening tool. ${ }^{32}$ It is a 9-point scale with pictographs from 1 (very fit) to 9 (terminally ill). A score of 5 or more is used to classify frailty. Judgement is made about the degree and severity of frailty based on the history and clinical examination. It has 
been validated to predict outcomes in hospitalised patients though not extensively studied in clinical settings. ${ }^{32}$ It was found to have good interrater reliability ${ }^{36}$ and predictive of mortality and functional decline when used by junior medical staff with no prior training on how to use the scale. ${ }^{37}$

The FRAIL scale has 5 components: fatigue, resistance, ambulation (slow walking speed), illness, loss of weight with 3 or more components needed to classify frailty. ${ }^{38}$

Performance based tests such as gait speed, timed up and go test (TUGT) ${ }^{39}$ and grip strength are more objective tests of functional ability and have been proven to predict adverse health outcomes. ${ }^{39}$ TUGT measures the time taken from sitting to rising from a chair, walking a specified distance on a flat surface and returning and sitting on the chair. ${ }^{3}$ These tests require special equipment such as a dynamometer for grip strength whereas gait speed and TUGT are not feasible for patients who are not ambulant.

Comprehensive geriatric assessment (CGA) is the established gold standard to evaluate older people which assesses medical, psychosocial, nutritional and functional ability. ${ }^{39}$ This may be difficult to provide in a resource limited setting as it requires time and the expertise of a multidisciplinary team such as a geriatrician, occupational therapist, physiotherapist and dietician.

Table I: Comparison of frailty measurements

\begin{tabular}{|c|c|c|c|}
\hline Frailty measurement (Year) & Description & Study population and procedure & Outcomes \\
\hline $\begin{array}{l}\text { Frailty Phenotype (2001) } \\
\text { Makary et al, Fried et al. }{ }^{27,29}\end{array}$ & $\begin{array}{l}3 \text { or more of } 5 \text { components: } \\
\text { Slow mobility, Weakness } \\
\text { Weight loss, Exhaustion } \\
\text { Low physical activity }\end{array}$ & $\begin{array}{l}\text { Prospective } \\
\geq 65 \text { yrs } \\
\text { all types of elective surgery }\end{array}$ & $\begin{array}{l}\text { Preoperative frailty associated with } \\
\text { increased risk of postoperative } \\
\text { complications and LOS } \\
\text { OR } 2.54,95 \% \text { CI } 1.12-5.77\end{array}$ \\
\hline $\begin{array}{l}\text { Frailty Index/ deficit } \\
\text { accumulation } \\
\text { (2001) } \\
\text { Rockwood and Mitnitski }{ }^{31}\end{array}$ & $\begin{array}{l}\text { Use of } 30+\text { variables } \\
\text { health deficits present/ } \\
\text { possible health deficits } \\
10 / 50 \text { deficits= frailty index } \\
\text { of } 0.20\end{array}$ & $\begin{array}{l}\text { Retrospective } \\
\geq 50 \text { yrs in the SHARE* }\end{array}$ & $\begin{array}{l}\text { Frailty predicts all-cause mortality at } 2 \\
\text { and } 5 \text { years } \\
\text { AUC }=0.77,95 \% \text { CI } 0.75-0.7 ; \\
\text { AUC }=0.75,95 \% \text { CI } 0.74-0.77\end{array}$ \\
\hline $\begin{array}{l}\text { Clinical Frailty Scale (2005) } \\
\text { Rockwood et } \mathrm{al}^{32} \\
\text { Bagshaw et } \mathrm{al}^{36}\end{array}$ & $\begin{array}{l}\text { Score of } 5 \text { or more out of } 9 \\
\text { Based on impairment in } \\
\text { mobility, function and } \\
\text { clinical judgement }\end{array}$ & $\begin{array}{l}\text { Prospective } \\
\geq 50 \text { yrs } \\
\text { Critically ill }\end{array}$ & $\begin{array}{l}\text { Frailty associated with higher in- } \\
\text { hospital mortality } \\
\text { OR } 1.81,95 \% \text { CI } 1.09-3.01 \\
\text { major adverse events } \\
\text { OR } 1.54,95 \% \text { CI } 1.01-2.37\end{array}$ \\
\hline $\begin{array}{l}\text { FRAIL scale } \\
(2012) \\
\text { Morley et } \mathrm{al}^{38}\end{array}$ & $\begin{array}{l}3 \text { or more of } 5 \text { components: } \\
\text { Fatigue, Resistance, } \\
\text { Ambulation } \\
\text { Illness, Loss of weight }\end{array}$ & $\begin{array}{l}\text { Retrospective } \\
\geq 65 \mathrm{yrs} \text { in long term care }\end{array}$ & $\begin{array}{l}\text { Frailty predicts mortality at } 6 \text { months } \\
\text { AOR } 3.36,95 \% \text { CI } 1.26-8.98 \\
\text { Pre-frailty associated with risk of falls } \\
\text { at } 6 \text { months } \\
\text { AOR } 2.62 ; 95 \% \text { CI } 1.25-5.54\end{array}$ \\
\hline $\begin{array}{l}\text { Modified Frailty Index } \\
(2012) \\
\text { Farhat et } \mathrm{al}^{28}\end{array}$ & $\begin{array}{l}\text { Frailty Index condensed to } \\
11 \text { variables** }\end{array}$ & $\begin{array}{l}\text { Retrospective } \\
\geq 60 \text { yrs } \\
\text { emergency general surgery }\end{array}$ & $\begin{array}{l}\text { Frailty index using mFI predicted } \\
\text { mortality at } 30 \text { days } \\
\text { OR } 11.70\end{array}$ \\
\hline $\begin{array}{l}\text { Edmonton Frailty Scale } \\
(2006) \\
\text { Rolfson et } \mathrm{al}^{40}\end{array}$ & $\begin{array}{l}\text { Score of } 8 \text { or more out of } 17 \text { : } \\
9 \text { frailty components } * * *\end{array}$ & $\begin{array}{l}\text { Prospective } \\
\geq 70 \text { yrs } \\
\text { variety of surgical procedures }\end{array}$ & $\begin{array}{l}\text { EFS }>7 \text { associated with increased } \\
\text { complications } \\
\text { OR } 5.02,95 \% \text { CI } 1.55-16.25 \\
\text { lower chance of being discharged } \\
\text { home }(40 \%, p<0.02)\end{array}$ \\
\hline $\begin{array}{l}\text { Robinson Index (2013) } \\
\text { Robinson et } \mathrm{al}^{35}\end{array}$ & Robinson Index\# & $\begin{array}{l}\text { Prospective } \\
\geq 65 \text { yrs } \\
\text { colorectal and cardiac surgery }\end{array}$ & $\begin{array}{l}\text { Frailty associated with } \\
\text { increased LOS and readmission } \\
(\text { AUC }>0.7) \\
\text { predicted postoperative complications } \\
(\text { AUC }>0.7)\end{array}$ \\
\hline
\end{tabular}

AUC $=$ Area under curve

$\mathrm{AOR}=$ Adjusted odds ratio

* Survey of Health Ageing and Retirement in Europe; **Diabetes mellitus, Dependent functional status, Chronic obstructive pulmonary disease or pneumonia, Congestive heart failure, Myocardial infarction, Angina or prior coronary intervention, Hypertension requiring medication, Peripheral vascular disease, Impaired sensorium, Prior transient ischemic attack or stroke without residual deficit, Cerebrovascular accident with residual symptoms; *** cognition, general health status, functional independence, social support, polypharmacy, nutrition, social support, mood, continence and functional performance; \#Katz Score $\leq 5$, Timed Up and-Go $\geq 15$ seconds, Charlson Index $\geq 3$, anemia $<35 \%$, Mini-Cog score $\leq 3$, albumin $<3.4 \mathrm{~g} / \mathrm{dL}$ and $\geq 1$ fall within six-months 
There is call for a standard measurement for consistent recognition of frailty worldwide, however the ideal frailty assessment tool is nnot yet determined. ${ }^{34}$ The ideal perioperative frailty assessment should not only be predictive of complications and mortality but also be easy to calculate by non-geriatricians. ${ }^{34}$

\section{Management}

Frailty is generally a progressive disease but can improve with appropriate interventions. ${ }^{38,41}$ Preventative measures appear to be the most effective. Exercise has been shown to increase functional performance, walking speed and balance. ${ }^{42}$ Prehabilitation, the concept of improving functional capacity before undergoing stress or surgery has been shown to improve perioperative functional exercise capacity. ${ }^{43}$ It is usually done with exercise training but there is a strong move to include nutrition and cognitive interventions. ${ }^{43}$ Interventions targeted at reducing polypharmacy may reduce the contribution of medications such as anticholinergics to impaired cognition and falls. Novel pharmaceutical approaches aim at addressing muscle mass loss and function. ${ }^{44}$

Enhanced recovery after surgery is a multimodal perioperative approach that aims to hasten recovery and improve outcomes in patients undergoing major surgery through components that begin preoperatively through to the postoperative period..$^{45}$

Preoperative interventions could include patient and caretaker education, prehabilitation and optimisation of comorbidities. Management of preoperative anaemia with iron supplementation is recommended to improve surgical outcome. $^{46}$ Intraoperative interventions could include appropriate selection of short acting anaesthetic agents with minimal cardiovascular effect, multimodal analgesia, fluid and temperature management as well as a minimally invasive surgical approach. Postoperative interventions focus on pain management, early removal of drains, prevention of nausea and vomiting as well as early nutrition and mobilisation. It is a cost-effective approach to reducing postoperative complications and minimising hospital stay after major surgery. ${ }^{45}$

Frailty assessments used preoperatively should identify those most vulnerable that could benefit from such interventions.

\section{REFERENCES}

1. Nguyen TN, Cumming RG, Hilmer SN. A Review of Frailty in Developing Countries. J Nutr Health Aging. 2015;19(9):941-6. Available at: https://doi.org/10.1007/s12603-015-0503-2

2. Organization WH. World report on ageing and health. Geneva: World Health Organization. 2015 [accessed 12 Aug 2018]. Available at: http://www.who.int/ageing/events/world-report2015-launch/en

3. Barnett SR. Perioperative Frailty. Advances in Anesthesia. 2014;1(32):119-31. Available at: https://doi.org/10.1016/j. aan.2014.08.012

4. Amrock LG, Deiner S. Perioperative frailty. Int Anesthesiol
Clin. 2014;52(4):26-41. Available at: https://dx.doi.org/10.1097/ AIA.0000000000000026

5. Tavani C. Public policy and the frail elderly: Dept. of Health, Education, and Welfare, Office of Human Development Service, Federal Council on Aging; 1978 [accessed 12 Aug 2018]. Available at: https://catalog.hathitrust.org/Record/007402032

6. Moorhouse P, Rockwood K. Frailty and its quantitative clinical evaluation. J R Coll Physicians Edinb. 2012;42(4):333-40. Available at: https://dx.doi.org/10.4997/JRCPE/.2012.412

7. Beggs T, Sepehri A, Szwajcer A, Tangri N, Arora RC. Frailty and perioperative outcomes: a narrative review. Can J Anaesth. 2015;62(2):143-57. Available at: https://doi.org/10.1007/ s12630-014-0273-z

8. Shisana O, Rehle T, Simbayi L, Zuma K, Jooste S, Zungu $\mathrm{N}$, et al. South African national HIV prevalence, incidence and behaviour survey, 2012. Available at: http://hdl.handle. net $/ 20.500 .11910 / 2490$

9. Thurn M, Gustafson DR. Faces of Frailty in Aging with HIV Infection. Curr HIV/AIDS Rep. 2017;14(1):31-7. Available at: https://doi.org/10.1007/s11904-017-0348-X

10. Pathai S, Gilbert C, Weiss HA, Cook C, Wood R, Bekker LG, et al. Frailty in HIV-infected adults in South Africa. J Acquir Immune Defic Syndr. 2013;62(1):43-51. Available at: https:// dx.doi.org/10.1097\%2FQAI.0b013e318273b631

11. Norman R, Matzopoulos R, Groenewald P, Bradshaw D. The high burden of injuries in South Africa. Bulletin of the World Health Organization. 2007;85(9):695-702.

12. Cesari M, Prince M, Thiyagarajan JA, De Carvalho IA, Bernabei R, Chan P, et al. Frailty: An Emerging Public Health Priority. J Am Med Dir Assoc. 2016;17(3):188-92. Available at: https://doi.org/10.1016/j.jamda.2015.12.016

13. Partridge JS, Harari D, Dhesi JK. Frailty in the older surgical patient: a review. Age Ageing. 2012;41(2):142-7. Available at: https://doi.org/10.1093/ageing/afr182

14. Clegg A, Young J, Iliffe S, Rikkert MO, Rockwood K. Frailty in elderly people. Lancet. 2013;381(9868):752-62. Available at: https://doi.org/10.1016/S0140-6736(12)62167-9

15. Ashar FN, Moes A, Moore AZ, Grove ML, Chaves PH, Coresh $\mathrm{J}$, et al. Association of mitochondrial DNA levels with frailty and all-cause mortality. J Mol Med (Berl). 2015;93(2):177-86. Available at: https://doi.org/10.1007/s00109-014-1233-3

16. Dodds C, Murray D. Pre $\square$ operative assessment of the elderly. Bja Cepd Reviews. 2001;1(6):181-4. Available at: https://doi. org/10.1093/bjaceaccp/mkh052

17. Newman AB, Gottdiener JS, McBurnie MA, Hirsch CH, Kop WJ, Tracy R, et al. Associations of subclinical cardiovascular disease with frailty. J Gerontol A Biol Sci Med Sci. 2001;56(3):M158-66. Available at: https://doi.org/10.1093/ gerona/56.3.M158

18. Woods NF, LaCroix AZ, Gray SL, Aragaki A, Cochrane BB, Brunner RL, et al. Frailty: emergence and consequences in women aged 65 and older in the Women's Health Initiative Observational Study. J Am Geriatr Soc. 2005;53(8):1321-30. Available at: https://doi.org/10.1111/j.1532-5415.2005.53405.x

19. Desquilbet L, Jacobson LP, Fried LP, Phair JP, Jamieson BD, Holloway M, et al. A frailty-related phenotype before HAART initiation as an independent risk factor for AIDS or death after HAART among HIV-infected men. J Gerontol A Biol Sci Med Sci. 2011;66(9):1030-8. Available at: https://doi.org/10.1093/ gerona/glr097

20. Morley JE, Vellas B, van Kan GA, Anker SD, Bauer JM, Bernabei R, et al. Frailty consensus: a call to action. J Am Med Dir Assoc. 2013;14(6):392-7. Available at: https://doi. 
org/10.1016/j.jamda.2013.03.022

21. Herr M, Robine JM, Pinot J, Arvieu JJ, Ankri J. Polypharmacy and frailty: prevalence, relationship, and impact on mortality in a French sample of 2350 old people. Pharmacoepidemiol Drug Saf. 2015;24(6):637-46. Available at: https://doi.org/10.1002/ pds. 3772

22. Lee DH, Buth KJ, Martin BJ, Yip AM, Hirsch GM. Frail patients are at increased risk for mortality and prolonged institutional care after cardiac surgery. Circulation. 2010;121(8):973-8. Available at: https://doi.org/10.1161/CIRCULATIONAHA.108.841437

23. Leung JM, Tsai TL, Sands LP. Brief report: preoperative frailty in older surgical patients is associated with early postoperative delirium. Anesth Analg. 2011;112(5):1199-201. Available at: https://dx.doi.org/10.1213\%2FANE.0b013e31820c7c06

24. Gu D, Dupre ME, Sautter J, Zhu H, Liu Y, Yi Z. Frailty and mortality among Chinese at advanced ages. J Gerontol B Psychol Sci Soc Sci. 2009;64(2):279-89. Available at: https:// doi.org/10.1093/geronb/gbn009

25. Hubbard RE, Fallah N, Searle SD, Mitnitski A, Rockwood K. Impact of exercise in community-dwelling older adults. PLoS One. 2009;4(7):e6174. Available at: https://doi.org/10.1371/ journal.pone. 0006174

26. Joseph B, Zangbar B, Pandit V, Fain M, Mohler MJ, Kulvatunyou N, et al. Emergency General Surgery in the Elderly: Too Old or Too Frail? J Am Coll Surg. 2016;222(5):805-13. Available at: https://doi.org/10.1016/j.jamcollsurg.2016.01.063

27. Makary MA, Segev DL, Pronovost PJ, Syin D, Bandeen-Roche $\mathrm{K}$, Patel P, et al. Frailty as a predictor of surgical outcomes in older patients. J Am Coll Surg. 2010;210(6):901-8. Available at: https://doi.org/10.1016/j.jamcollsurg.2010.01.028

28. Farhat JS, Velanovich V, Falvo AJ, Horst HM, Swartz A, Patton $\mathrm{JH}$, Jr., et al. Are the frail destined to fail? Frailty index as predictor of surgical morbidity and mortality in the elderly. $\mathrm{J}$ Trauma Acute Care Surg. 2012;72(6):1526-30; discussion 30-1. Available at: https://doi.org/10.1097/TA.0b013e3182542fab

29. Fried LP, Tangen CM, Walston J, Newman AB, Hirsch C, Gottdiener J, et al. Frailty in older adults: evidence for a phenotype. J Gerontol A Biol Sci Med Sci. 2001;56(3):M14656. Available at: https://doi.org/10.1093/gerona/56.3.M146

30. Mitnitski AB, Mogilner AJ, Rockwood K. Accumulation of deficits as a proxy measure of aging. ScientificWorldJournal. 2001;1:323-36. Available at: http://dx.doi.org/10.1100/ tsw. 2001.58

31. Rockwood K, Mitnitski A. Frailty defined by deficit accumulation and geriatric medicine defined by frailty. Clin Geriatr Med. 2011;27(1):17-26. Available at: https://doi. org/10.1016/j.cger.2010.08.008

32. Rockwood K, Song X, MacKnight C, Bergman H, Hogan DB, McDowell I, et al. A global clinical measure of fitness and frailty in elderly people. CMAJ. 2005;173(5):489-95. Available at: https://doi.org/10.1503/cmaj.050051

33. Searle SD, Mitnitski A, Gahbauer EA, Gill TM, Rockwood K. A standard procedure for creating a frailty index. BMC Geriatr. 2008;8:24. Available at: https://doi.org/10.1186/1471-2318-824

34. Hubbard RE, Story DA. Patient frailty: the elephant in the operating room. Anaesthesia. 2014;69 Suppl 1:26-34. Available at: https://doi.org/10.1111/anae.12490

35. Robinson TN, Wu DS, Pointer L, Dunn CL, Cleveland JC,
Jr., Moss M. Simple frailty score predicts postoperative complications across surgical specialties. Am J Surg. 2013;206(4):544-50. Available at: https://doi.org/10.1016/j. amjsurg.2013.03.012

36. Bagshaw SM, Stelfox HT, McDermid RC, Rolfson DB, Tsuyuki RT, Baig N, et al. Association between frailty and short- and long-term outcomes among critically ill patients: a multicentre prospective cohort study. CMAJ. 2014;186(2):E95-102. Available at: https://doi.org/10.1503/cmaj.130639

37. Gregorevic KJ, Hubbard RE, Lim WK, Katz B. The clinical frailty scale predicts functional decline and mortality when used by junior medical staff: a prospective cohort study. BMC Geriatr. 2016;16:117. Available at: https://doi.org/10.1186/ s12877-016-0292-4

38. Morley JE, Malmstrom TK, Miller DK. A simple frailty questionnaire (FRAIL) predicts outcomes in middle aged African Americans. J Nutr Health Aging. 2012;16(7):601-8. Available at: https://doi.org/10.1007/s12603-012-0084-2

39. Kristjansson SR, Nesbakken A, Jordhøy MS, Skovlund E, Audisio RA, Johannessen H-O, et al. Comprehensive geriatric assessment can predict complications in elderly patients after elective surgery for colorectal cancer: a prospective observational cohort study. Critical reviews in oncology/ hematology. 2010;76(3):208-17. Available at: https://doi. org/10.1016/j.critrevonc.2009.11.002

40. Rolfson DB, Majumdar SR, Tsuyuki RT, Tahir A, Rockwood K. Validity and reliability of the Edmonton Frail Scale. Age Ageing. 2006;35(5):526-9. Available at: https://doi.org/10.1093/ageing/ afl041

41. Clegg A, Young J, Iliffe S, Rikkert MO, Rockwood K. Frailty in elderly people. Lancet. 2013;381(9868):752-62. Available at: https://doi.org/10.1016/S0140-6736(12)62167-9

42. Gillespie LD, Robertson MC, Gillespie WJ, Sherrington C, Gates S, Clemson LM, et al. Interventions for preventing falls in older people living in the community. Cochrane Database Syst Rev. 2012(9):CD007146. Available at: https://doi.org/ 10.1002/14651858.CD007146.pub3

43. Carli F, Charlebois P, Stein B, Feldman L, Zavorsky G, Kim DJ, et al. Randomized clinical trial of prehabilitation in colorectal surgery. British Journal of Surgery. 2010;97(8):1187-97. Available at: https://doi.org/10.1002/bjs.7102

44. Muir SW, Montero-Odasso M. Effect of vitamin D supplementation on muscle strength, gait and balance in older adults: a systematic review and meta-analysis. J Am Geriatr Soc. 2011;59(12):2291-300. Available at: https://doi.org/10.111 1/j.1532-5415.2011.03733.x47.

45. Ljungqvist O, Scott M, Fearon KC. Enhanced Recovery After Surgery: A Review. JAMA Surg. 2017;152(3):292-8. Available at: https://doi.org/10.1001/jamasurg.2016.4952

46. Goodnough LT, Maniatis A, Earnshaw P, Benoni G, Beris $\mathrm{P}$, Bisbe E, et al. Detection, evaluation, and management of preoperative anaemia in the elective orthopaedic surgical patient: NATA guidelines. Br J Anaesth. 2011;106(1):13-22. Available at: https://doi.org/10.1093/bja/aeq361 